\title{
Wellbeing and Welfare: A Psychosocial Analysis of Being Well and Doing Well Enough
}

\author{
DAVID TAYLOR \\ Faculty of Health and Social Science, University of Brighton, Mayfield House, Falmer, \\ Brighton BN1 9PH \\ email: d.taylor@bton.ac.uk
}

\begin{abstract}
Wellbeing is increasingly supplanting welfare as a central political goal for social and public policy. In academic social policy, some writers have suggested that a focus on wellbeing allows us to consider a 'fully rounded humanity' whereas welfare focuses on economic utility. This article avoids this polarisation and proposes a generative and relational view of wellbeing and welfare as mutually constitutive. It adopts a trans-disciplinary critical psychosocial perspective to reveal highly normative views of wellbeing and agency employed in these political and academic discourses. It proposes a view of agency for wellbeing which is contextual, includes non-rational action and is oriented to being well enough with others. Instead of a concern with outcome measures such as happiness, it proposes a view of wellbeing as a process which varies according to context. Drawing on the notion of 'thick' and 'thin' needs, the specific content of wellbeing is seen as generated through 'close' and 'distant' relationships. This approach challenges contemporary policy responses to wellbeing which are individualised and marketled and suggests that a question for social policy is: which relationships and contexts are generative of individual wellbeing and welfare?
\end{abstract}

\section{Introduction}

In the past decade, the promotion of wellbeing has become a central political goal for social and public policy. In 2009, French President Sarkozy's Commission on the Measurement of Economic Development and Social Progress proposed to shift emphasis from measuring economic production to measuring people's wellbeing. Aimed at political leaders, policymakers, academics and civil society activists, the report sought to stimulate global initiatives and debates over 'societal values, for what we, as a society, care for and whether we are really striving for what is important' (Stiglitz, Sen and Fitoussi, 2011). It echoes the principles of the United Nations Human Development Index which sees, 'human wellbeing as the purpose, the end, of development' (UNDP website, 2011). In the United Kingdom in 2000, the New Labour Government introduced the 'wellbeing power', a duty on the part of English local government to promote economic, social 
or environmental wellbeing of an area (HM Government, 2000). In Scotland, the Local Government Act of 2003 grants the authority to 'advance wellbeing' to Scottish local authorities. The last UK parliament established an All-Party Parliamentary Group on 'wellbeing economics' which aimed to challenge Gross Domestic Product (GDP) as the government's main indicator of national success and promote new measures of societal progress. In 2010, the new UK Prime Minister, David Cameron, announced that the coalition government would require the UK Office for National Statistics (ONS) to devise measures of progress other than GDP. In a speech to the Treasury in November 2010, he argued, 'just as the GDP figures don't give the full story of our economy's growth - but do give a useful indicator of where we're heading - so this new measure won't give the full story of our nation's well-being but will give us a general picture of how life is improving' (Cameron, 2010). The ONS was asked to lead a National Wellbeing Project to establish the key areas that matter most to people's wellbeing - an approach recommended by the think-tank New Economics Foundation (nef), amongst others, which lobbies for the replacement of GDP with a 'national account of wellbeing' and 'calls for governments to directly and regularly measure people's subjective well-being: their experiences, feelings and perceptions of how their lives are going, as a new way of assessing societal progress' (nef website, 2010).

At the same time, there has been a growing interest in wellbeing in academic social policy. A number of writers have recently debated the concept of wellbeing and its relationship to welfare. Jordan (2008) promotes the notion of wellbeing because it allows us to consider what he calls 'social value', rather than an economic understanding of utility which he associates with welfare. It foregrounds personal relationships, trust and participation rather than consumption, and focuses on the creation and exchange of 'social value' through relationships at the level of culture rather than economic value through contract. Searle (2008) examines a variety of approaches to wellbeing and welfare, concluding that that the central concern of policy should be the promotion of 'contentment'. Others, like the Wellbeing and Development (WeD) group at the University of Bath identify the aim of wellbeing and development as a 'fully rounded humanity' (Gough, McGregor and Camfield, 2007:3). Wellbeing, for this group, is seen as a wider-ranging concept than welfare and one which 'cannot be conceived just as an outcome, but must be understood also as a process' (2007: 5). Their approach draws on universal theories of human need developed originally by Doyal and Gough $(1984,1991)$ and the work of Amartya Sen and Martha Nussbaum on capabilities. It utilises three frameworks: resource profiles, human needs and quality of life. Also writing from a development perspective, Wood and Newman make a strong argument for wellbeing replacing welfare as the central concern for social development and social policy where 'capacity building becomes more important than social protection' (2005: 1), and they talk 
of 'wellbeing regimes' in place of 'welfare regimes' as a focus for comparative analysis. Dean (2005), in a recent introductory text, defines social policy as the study of human wellbeing and argues more recently that 'the advantage of wellbeing as a term is that it can turn our attention to the positive aspects of social policy, as opposed to the negative aspects relating to social problems' (Dean, 2010: 100).

To some extent, this refocusing of politics and policy on positive issues of 'rounded humanity' is to be welcomed. It allows us to consider what it means to 'be well' alongside what it means to 'do well'. It raises questions of human meaning, happiness, personal experience and social recognition as well as access to material goods and resources. It suggests that the purpose of social policy might be the promotion of an individual ontological security which goes beyond the traditional focus on redistribution and possession.

However, the concept of wellbeing needs to be treated with caution. It can serve many ends and has been criticised for its recent political association with an individualised and marketised view of social provision. Sointu (2005: 255), for example, has argued that it is associated with the move from 'subjects as citizens to subjects as consumers' and Edwards and Imrie (2008:337) have argued that it relies on notions of 'self-help and therapy or individuated actions and (self) responsibilities'. It is argued here that implicit in contemporary notions of wellbeing are a range of assumptions about the nature of the individual, the social and of agency which are highly normative. I also argue that a preoccupation with individual wellbeing alone has the potential to detract from the continued importance of collective welfare and the social provision of the material conditions in which much individual wellbeing is lived and felt. A different language is required to re-articulate wellbeing and welfare which supports collectivist and solidarist orientations and relations and avoids the marginalisation of social welfare. In this article, I argue that wellbeing should be seen as a process, not simply an outcome, that it is relational and contextual and that, for users of welfare services, it cannot be understood independently of the social provisions of the welfare state.

\section{Approaches to wellbeing}

Most accounts of wellbeing are concerned with understanding how individuals can act in ways which make them feel well and be well, or put another way, can exercise agency for wellbeing. They mostly try to balance subjective wellbeing (SWB) - self-reported feelings of happiness and general wellbeing, with objective wellbeing $(\mathrm{OWB})$ - a list of objective social determinants such as age, health, environment, employment and personality (Van Hoorn, 2007). The WeD Group has similarly produced an approach to wellbeing and development which takes account of the 'objective circumstances of the person and their subjective assessment of these' (Gough, McGregor and Camfield, 2007: 5). 
So wellbeing for individuals is seen as cognitive, affective and material; that is, it involves reflections on individual experience and social circumstances, often in comparison with those of others, and subjective feelings about the quality and substance of those experiences. Wellbeing, therefore, is the product of the social conditions which enable a positive experience of self. It is selfefficacy in the context of supportive social circumstances. As already suggested, wellbeing on this view often supplants state welfare as normative project. In many political discourses, the receipt of welfare benefits and services is seen to lead to state dependency and lack of self-efficacy rather than a highly valued individual autonomy believed to be at the heart of wellbeing. Indeed, wellbeing as 'independence' - the ability to operate without recourse to state support - is characterised as the product of genuine agency and counter-posed to the notion of 'welfare dependency' or welfare as lack of agency. Wellbeing is equated with autonomous individuals and welfare is equated with a passive dependence on social provision. What is crucially missing in these accounts is recognition of the inter-dependence of wellbeing and welfare and a conception of the relational nature of both. Welfare may provide the conditions in which genuine agency can take place and agency itself may be found within social relationships as much as in autonomous individual action.

In order to produce a different reading of wellbeing, I adopt a transdisciplinary 'psychosocial' approach (see Stenner and Taylor, 2008) to understand the relationship between the individual and the social. I also draw on 'relational' views of wellbeing understood as inter-subjective relations and relations of time, space and location. These support the view of wellbeing as a process rather than an outcome. With Gough, McGregor and Camfield (2007: 5), I argue it is a dynamic concept: 'states of wellbeing/illbeing are continually produced in the interplay within the social, political, economic and cultural processes of human social being'. I draw on philosophical notions of 'thick' and 'thin' needs, that is the distinction between what individuals need, on the one hand, to flourish (that is, what enables an individual to be 'well') and, on the other, simply to survive (that is, that which enables an individual to 'be'), and argue that wellbeing also has 'thick' and 'thin' dimensions.

However, if we accept that wellbeing is relational, I suggest that thick and thin wellbeing may be based in either close or distant relationships. By close relationships, I refer to those which are closer in an inter-personal and/or locational sense. They tend to have a richer or denser structure with high emotional content and are often associated with friendship, family, care or community. By distant relationships, I mean those which are more formalised and impersonal and may include those with providers of public or private services, consumption and market exchanges or even the more chance relationships experienced in open social milieux. In some contexts, it may be that relationships which are closer or 'denser' are those which produce a thicker sense of wellbeing 
or 'flourishing' and those which are more distant are the ones within which individuals experience a 'thinner' sense of wellbeing. Such an interpretation draws on the traditional Aristotelian binary of eudaimonia and hedonia. The former refers to a deeper sense of satisfaction and fulfilment, whist the latter to a more superficial sense of happiness. This distinction informs many contemporary wellbeing studies (see Deci and Ryan, 2006). However, my central point is different: the key issue is not one simply of the relative depth of individualised wellbeing - that deeper individual wellbeing or 'self-fulfilment' is always to be preferred as a normative aim to an apparently more superficial sense of happiness - that eudaimonia is always to be preferred to hedonia. Nor is it that close relationships are always more constitutive of flourishing. Indeed, they can equally be productive of its opposite - a range experiences and emotions that are destructive of wellbeing. It is rather to argue that if we take a relational view of wellbeing, the issue is: which type of social relationships are constitutive of which kinds of wellbeing for any individual in different contexts and over their life-course?

Lastly, I also argue that accounts of wellbeing located in a cognitive rational actor perspective risk not only marginalising the 'affectual' dimension of subjectivity - in this case the meaning that wellbeing has for individuals in time and location - but also work with a highly normative and, in some cases, exclusionary view of agency. As a result, I suggest a conception of wellbeing and welfare as interdependent. By this I mean that the provision of social welfare serves as the context and condition for individual wellbeing. Thus, the specificity of wellbeing should be approached from a theoretical perspective but understood and investigated in an empirical context.

\section{Psychosocial studies: inter- and trans-disciplinarity}

Reflecting on the problems of researching wellbeing and poverty in a development context, Phillipa Bevan (2007: 311) argues for a 'post or multi-disciplinary approach' that draws on anthropology, sociology, political theory, economics and psychology. She acknowledges that this raises many epistemological, ontological, normative and methodological issues. I argue that these can best be addressed through a transdisciplinary psychosocial analysis. This can aid our understanding of constructions of the object of knowledge and the generation of knowledge as deployed across a range of political discourses and academic studies in the social sciences.

There has been a steady growth recently in psychosocial studies, especially associated with micro-level analyses focussing on subjectivities and experience in social context, but I argue that a psychosocial approach can be equally helpful in understanding macro issues of social and public policy, especially in relation to wellbeing and welfare. 
A simple psychosocial approach reminds us that wellbeing cannot be abstracted from a consideration of social relations of welfare and that social provisions of the welfare state play a constitutive role in human subjectivity and inter-subjectivities. It also suggests that all subjectivity is experienced and 'enacted' in the context of social relations.

Contemporary psychosocial approaches have arisen as part of an 'affectual turn' in the social sciences. Just as the social sciences previously experienced a 'cultural turn' in which analyses focused on the discursive construction of meaning as symbolic and textual, psychosocial approaches attend to bodily and emotional experience and the expressive nature of subjectivity, intersubjectivities and social relations. From this perspective, psychosocial studies allows us to consider the expressive, relational and processual nature of wellbeing and welfare. As a result of these orientations, psychosocial studies are also essentially methodologically plural and interpretive, concerned with deepening understanding rather than producing causal explanation (cf. Frosh, 2003) and concerned with affect as much as text.

Stenner and Taylor (2008) have described different approaches to psychosocial studies based around different orientations towards knowledge. Psychosocial studies are described as either multi-disciplinary, inter-disciplinary or trans-disciplinary. Stenner (2010: 1) goes on to distinguish the 'transdisciplinary dialect of psychosocial studies from the factors and variables dialect; the psychoanalytical sociology dialect; and the social constructionist dialect'. He suggests 'that these other dialects remain either multi- or inter-disciplinary in nature, although each has trans-disciplinary moments and potential'. In short, in multi-disciplinary psychosocial studies, each discipline brings their own 'level of abstraction' to the study of an object, but each discipline remains unchanged as a result. In a practical example, this theoretical approach may guide multiprofessional practices where a range of professionals bring their own expertise and disciplinary knowledge to bear on a social problem without their professional practice or the under-pinning knowledge base being transformed in the process.

In inter-disciplinary psychosocial studies, there is 'a transfer of concepts and methods from one discipline to another in order to solve problems' (Stenner and Taylor, 2008: 430). Psychoanalytical sociology is a good example of this approach, as is the work of Cooper and Lousada (2005) on 'borderline welfare'. Interdisciplinary psychosocial studies is about establishing 'trade routes' between the disciplines in which concepts elaborated in one disciplinary context may be deployed or adapted in another. Disciplinary knowledge may be transformed as a result, but this is neither the aim nor the necessary outcome.

Trans-disciplinary psychosocial studies is more difficult to grasp and is at times more abstract as it focuses on that which 'escapes disciplinary knowledge' (Stenner and Taylor, 2008: 431). To elaborate: 'A trans-disciplinary psychosocial studies would deal with the "space between" and would be inclusive enough 
to move between the abstractions of different sciences ... taking into account the situated knowledge and experience of non-specialists and other forms of subjugated knowledge. The knowledge that results is always a hybrid knowledge that combines features and themes that are not usually assembled on the same epistemological plane' (Stenner and Taylor, 2008: 431). It is not 'anti-disciplinary' but is more interested in the analysis of that which is not always grasped though existing disciplinary approaches and abstractions.

Taking a critical trans-disciplinary approach to wellbeing and welfare may help us uncover particular constructions of the individual and the social and their normative implications. In particular, SWB approaches to wellbeing tend towards a model of the individual abstracted from social context and OWB approaches to wellbeing tend towards a representation of the social determinants of wellbeing as a simple set of material circumstances untroubled by social relations of power.

\section{Wellbeing and welfare: being well and doing well}

A trans-disciplinary psychosocial approach must start by problematising received disciplinary knowledge of the object of study as located in its host disciplines. Wellbeing has traditionally been approached through the disciplines of psychology and, increasingly, economics with a strong anchor in individual happiness and rational action.

Within psychology, the dominant approach to wellbeing has been through self-reported happiness studies, where wellbeing is seen as an 'outcome'. These attempt to grasp subjective wellbeing through single or multiple rating scales in which subjects are asked about their current state of happiness and, by implication, their wellbeing. Such studies have an affectual and a cognitive and dimension. The affectual dimension refers to 'the presence of positive affect and the absence of negative affect' and the cognitive dimension is 'an informationbased appraisal of one's life for which people judge the extent to which their life so far measures up to their expectations and resembles their envisioned "ideal" life' (Van Hoorn, 2007: 2).

Some researchers have tried to move beyond this simple 'happiness' approach to look at other positive emotions, such as excitement, pleasure, control and engagement, and beyond the subjective approach to wellbeing to include the 'social determinants' of wellbeing (cf. van Hoorn, 2007). However, many of these approaches work with the notion of the individual marshalling positive affect and exhibiting the necessary capabilities for agency as central to wellbeing. The latter is seen as an outcome achieved via the deployment of these capabilities. As such, these conceptions employ a strongly individualised conception of agency for wellbeing. Whilst this approach relates individual actions to social determinants, it nevertheless employs a unitary notion of the rational actor fully in control of a set of actions cognitively oriented toward self-fulfilment. 
For Johann Seigrist (2003: 6), wellbeing is self-efficacy. It is a 'positive experience of self (which) is contingent on a social environment that provides opportunities of belonging, acting or contributing and receiving favourable feedback'. This is certainly a socialised view of the individual focussing on the social context in which effective agency can take place. It is, however, still highly cognitive and based on a rational appraisal of one's social conditions and possession of 'capabilities'. It derives from a 'favourable self-evaluation of competence and capability to achieve expected outcomes' (2003: 6). This view of the individual rests on a number of key assumptions about successful action or agency. As Edwards and Imrie (2008) point out, in an account of the limitation of current wellbeing ideas in relation to disability, 'life satisfaction is related to particular idealised forms of behaviour or ways of being (including being healthy, fit, employed and engaged in civic society) which engender positive emotional states. The perceived role of a "politics of happiness", then, is to minimise, or eradicate, negative emotions through interventions which seek to engage individuals, or create conditions for them to pursue ways of living which promote wellbeing' (2008: 338). They point out that, 'such an analysis may, however, ignore the significant societal barriers that particular individuals, such as disabled people, experience in participating in a society as self-determining citizens and, through a reductive analysis of emotions, further stigmatise those that do not meet the wellbeing ideal' (2008: 338). A picture begins to emerge of a highly normative set of social institutions and idealised individual behaviours which are seen as productive of individual happiness and self-fulfilment.

Wellbeing economics extends concern with individual happiness to understanding how economic factors, that include GDP growth but also sustainable development, can contribute to individual wellbeing. A HM Treasury paper (2008: 12, emphasis added) argues for a combined subjective and objective approach to wellbeing but, nevertheless, claims that 'arguments to support changing macro-economic policy priorities for stable economic growth to targeting wellbeing are inconclusive'. In something of a contradiction, however, it goes on, 'the evidence points to the continued need for growth and promoting macro-economic stability and targeting of the specific sources of ill-being. It highlights particular priorities: alleviation of chronic illness including mental illness; reducing unemployment and inflation; strengthening relationships and social capital; and, ensuring high quality governance' (2008: 12).

This link between positive mental health, employment and wellbeing is central to the concerns of both positive psychologists and economists working in this territory. The much vaunted investment of $\mathfrak{E} 600$ million on the part of the last UK Labour Government in 'improving access to psychological therapies' (IAPT) was justified by happiness economist Richard Layard not only because of the need to deal with the crisis of chronic mental health in the community, but also because of the need to get people back to work and off benefits. As the British 
Association for Counselling and Psychotherapy noted: 'Layard reasoned that funding by the Department of Health $(\mathrm{DH})$ to improve provision of psychological therapies in the treatment of depression and anxiety, would positively impact on the number of people who are fit to work. This increase would consequently reduce the cost of Incapacity Benefit for this section of the population, leading to potential savings for the Department of Work and Pensions (DWP). In bringing together prevalence statistics for depression and anxiety, costs of training and employing therapists, potential cost savings in the DWP, and the benefits to individuals and society of improved mental health and wellbeing, Layard was able to make a strong case for investment by central government' (see BACP website, 2010).

In all these approaches, 'negative affect', or in this case anxiety or depression, are seen as individual behavioural characteristics and something to be removed as a barrier to wellbeing. Therapeutic interventions aimed at individual behavioural change can be driven down to the most minimal level. For example, patients with anxiety or mild depression may be offered 'low intensity' cognitive behavioral support via the IAPT scheme. As a first stage of intervention, this can typically consist of a self-help manual. The dominance of this individualised approach may then drive mental health policy much more widely, so that work with co-morbid and complex patients, which sees complex negative emotions as a resource to be drawn on within the therapeutic relationship (rather than something to be overcome behaviorally through individual self-help), may suffer reduced funding due to its lack of easy reduction to simple behavioural outcome measures located in rational individual self-help programmes and captured in happiness measures and return-to-work statistics.

There are commentators such as Furedi (2003), who see self-help therapy as characteristic of an over-intrusion of politics into the subjective realm and an attempt to dress up social problems as emotional problems. This sociological critique is founded upon a belief in a clear distinction between the social and the psychological, which I believe is unwarranted. The difficulty is not the intrusion of one discreet sphere, the emotional, into another, the social, but that the mutual nature of the social and inter-personal relationships are glossed over in the growth of self-help therapy and reduced to invocations to take autonomous rational action in pursuit of one's own wellbeing, often ignoring the social and economic issues associated with a social relations perspective. Stephen Frosh reminds us of the importance of the emotional and the sub-conscious, in particular projective identification and fantasy, for understanding the social and the political (Frosh, 2003: 1554). The issue is not the politicisation of the emotional, rather, the reduction of the emotional to the politics of self-help.

The nef, as noted earlier, campaigns for national accounts of wellbeing, but their conception of individual action for wellbeing seems firmly based in the notion of rational cognitive action on the part of individuals fully integrated into 
civic life. They advocate 'five steps' to individual wellbeing:

'Connect: With the people around you. With family, friends, colleagues and neighbours. At home, work, school or in your local community. Think of these as the corner of your life and invest time in developing them. Building these connections will support and enrich you every day. Be active: Go for a walk or a run. Step outside. Cycle. Play a game. Garden. Dance. Exercising makes you feel good. Most importantly, discover a physical activity you enjoy and one that suits your level of mobility and fitness; Take notice: Be curious. Catch sight of the beautiful. Remark on the usual. Notice the changing seasons. Savour the moment, whether you are walking to work, eating lunch or talking to friends. Be aware of the world around you and what you are feeling. Reflecting on your experiences will help you appreciate what matters to you; Keep learning: Try something new. Rediscover an old interest. Sign up for that course. Take on a different responsibility at work. Fix a bike. Learn to play an instrument or how to cook your favourite food. Set a challenge you will enjoy achieving. Learning new things will make you more confident as well as being fun; Give: Do something nice for a friend, or a stranger. Thank someone. Smile. Volunteer your time. Join a community group. Look out, as well as in. Seeing yourself, and your happiness, linked to the wider community can be incredibly rewarding and creates connections with the people around you' (nef website, 2010).

There can be no doubting the normative nature of the assumptions about individual action for wellbeing described here. As Edwards and Imrie (2008: 340-1) point out, the wellbeing agenda 'sets up happiness as a state of being that can be achieved through particular forms of idealised behaviour, thereby reinforcing particular social norms ... happiness becomes an individual virtue to which we should all aspire'.

Happiness economics and the positive psychology movement, then, come together around the notion that wellbeing is achieved when individuals are able to act autonomously to achieve maximum individual happiness independently of so-called welfare dependency. These approaches reinforce a view of wellbeing as based in individual autonomous action.

\section{Wellbeing and agency}

Ryan and Sapp (2007: 71), who see wellbeing as an aim of agency, argue that 'wellbeing concerns a person's capacity for optimal functioning and encompasses not only the issue of physical health, but also a sense of interest in one's surroundings, a confidence in being able to formulate and act to fulfil important goals and the motivation and energy to persist in the face of obstacles. A well being is able to maintain its vitality and to thrive within its everyday ecological environment.'

This is a positive aim for social and public policy, but a high normative bar to set for individual agency for wellbeing. Such a 'being' would employ a highly cognitive active subjectivity. But how frequently can this active subjectivity be deployed without reference to group solidarities, social movements or other social forces directed to achieving the social determinants of welfare which may be pre-conditions of individual wellbeing? The rational agent above is confident, unitary and autonomous, striving for personal wellbeing and possessed 
of the social capital and personal skills and resources to achieve desired ends. Of course, taking rational action in pursuit of wellbeing may be positive, but what about those experiencing 'negative emotions' in the context of close or distant relationships or those experiencing dehumanising effects of unresponsive service provision or exclusion from market-based consumption? The view above runs the risk of instituting a deficit model of affective non-rational action or of those actions aimed at the simple maintenance of personal integrity in the context of threat, and of ignoring the desire to be with others simply to gain a sense of security and self-worth. As Williams (1999), drawing on Winnicott, has argued, the normative aim of welfare provision should include the creation of circumstances and relationships which allow individuals to achieve a sense of wellbeing which is 'good enough' - that is, a sense of integrity, respect and recognition but not necessarily one in which individuals are judged against a benchmark of 'perfection' or, in this case, a model of perfection which consists of the ability to act rationally in pursuit of complete self-fulfilment.

I would argue that there are, at least, three reasons, why such a model is insufficient. Firstly, it tends toward a theory of wellbeing which equates it with a particular view of agency as rational cognitive action. Secondly, it tends towards a down-playing of negative emotions, complexity and sub-optimal conditions which may produce contexts in which being well enough is a perfectly reasonable ambition for agency. Thirdly, it utilises notions of participation in the civic sphere via a range of capabilities which may not be open to all individuals. As well as the danger of 'ablist' assumptions noted by Edwards and Imrie (2008), we should be wary of other normativities around constructions of the civic spaces and activities which such 'well' individuals are encouraged to orient themselves. In fact, if we set the bar as the fully self-actualising individual, we may end-up with a deficit model of those unable to measure up to it. It can lead to an assessment of other non-normalised forms of individual agency as failed subjectivity and agency.

The well agent referred to by Ryan and Sapp (2007), for example, would certainly be well and do well, indeed they might be very well. And, indeed, a social and public policy which truly enabled all users of its services to be that well might be an effective social policy for those people. But social relations are constitutive of complex and contradictory subjectivities and produce actions which are not always self-efficacious, but can be destructive, nihilistic or selfsabotaging. Also, the capacity to act is not simply an individual resource, but is contextual and depends upon the ability to mobilise self in the context of and with others - it is relational. In some contexts, people may feel well enough if they are able to get by in the context of internal and external threat and regulation or alternatively they may identify more limited aspirations for themselves. Their sense of wellbeing may also depend upon the relationships they are able to form 
with a variety of others. These may vary according to social and personal context and for individuals over time. Some of us may struggle simply to get by and our ambitions for personal wellbeing may be as much directed at securing the social conditions which allow us to form reasonable relationships with others. Who these key others are will depend on a range of personal and social circumstances and is a matter of empirical investigation.

There is an important sense, then, in which we need to aware of limited agency and negative capability which is concerned simply with maintaining personal integrity and unity and is not always about seeking clear action-oriented outcomes. The importance of this negative capability - a state of uncertainty rather than a relentless striving for fulfillment - is emphasised by Cooper and Lousada (2005) when they refer to the psychoanalyst Wilfred Bion quoting Keats in a letter to his brother in 1817 on 'negative capability: when a man is capable of being in uncertainties and doubts without any irritable reaching after fact and reason'. Uncertainties and doubts need not be seen as counter to effective wellbeing, yet wellbeing has become directly linked to positive outcome-oriented action and tends towards the acquisition of behaviors which are seen as supportive of independence and clear and effective self-help.

In contemporary political discourse, this positive cognitive action orientation sits easily alongside the active consumer who purchases self-help solutions to individual wellbeing. The sociologist Elizabeth Sointu $(2005,2006)$ has examined the rise of alternative therapies as part of a transition in subjectivity: 'the increasing popularity of the ideal of wellbeing appears to reflect shifts in perceptions and experiences of individual agency and responsibility. In particular, dominant discourses of wellbeing relate to changes in subjectivity ... In a consumer society, wellbeing emerges as a normative obligation chosen and sought after by individual agents' (2005: 255).

Erich Fromm (2008) described the transition from personal integrity to acquisition over fifty years ago as the triumph of 'having', that is participating in public commodified relationships in which possession is the orientation and commodities are the object, over simply 'being'. And as Paul Hoggett (2001: 53), reflecting on the difficulty of always turning external resources into the power to act, says, 'an appreciation of the passive voice may also enable us to develop a more nuanced and gendered account of the stressful and disempowering environments that many welfare subjects experience, where individuals are surrounded by constraints which cannot simply be turned into resources'. He also notes, 'social policy must not shirk a confrontation with our negative emotional capabilities, that is, the capacity for self-destructiveness and destructiveness towards others which both individual and groups are more than capable of (2001: 53). For health and social care professionals, 'being with' service users and enabling them to be with others in supportive relationships is an important approach to creating the conditions for being 'well enough'. This is a contrasting approach to that 
which seeks simply to enable autonomous acts of independent agency aimed at maximum self-fulfillment.

\section{Agency}

At the heart of some of these assumptions is the Weberian notion of agency as the basis for genuine individual wellbeing, and in much contemporary social theory agency is taken as axiomatic. But I suggest that there has not been adequate attention to, or theorisation of, agency in much of this work.

In broad Weberian terms, agency has been understood as action in social context under intention and directed towards a chosen end. To possess agency, the individual must have the ability to define their goal, the capability to act independently on their intention and the resources to realise that intention. In this approach, however, agency is characterised as individual rational cognitive action. More recent social policy, especially when influenced by utilitarian assumptions, has assumed that political actions can engineer individuals to make rational selfinterested choices in relation to their own wellbeing. The welfare subject who has agency may be seen as participating in decision-making and accessing resources, whether public or private, to achieve their own wellbeing. Agency and wellbeing on this model are both individualised and 'responsibilised' (cf. Bauman, 2003). Active agents are to become independent of collectivised social provision in the form of the welfare state and transcend the complex web of inter-subjectivities with its messy emotional dynamics and possible negative affect. If, however, we take a post-liberal view of subjectivity as relational and non-unitary, we may arrive at a more nuanced understanding of agency and wellbeing which is less oppositional to welfare and more capable of taking account of the relational complexities of subjectivity.

As Paul Hoggett has powerfully suggested, 'there is nothing necessarily constructive about agency and we should be aware of smuggling normative assumptions into our thinking here, as if agency is good and absence of agency is bad. Just as we can be destructive agents so also at times we can be constructive in our dependency and powerlessness ... we need a model of self as object as well as self as agent' (Hoggett, 2001: 43). I would add that we need a model of the self as relational and we need an understanding that agency for wellbeing defined as self-fulfillment especially in the context of market-based social institutions is highly normative and limited in its understanding of the complexity of agency.

Instead of this universal rational cognitive actor approach, we might suggest that individual wellbeing and agency can only be understood in the context of specific social relations. The problem with dominant notions of wellbeing is that, whilst they may acknowledge that wellbeing has to be understood in the context of a range of social determinants, they can fail to analyse the social and relational nature of those determinants - they become abstractions of the social acting as a neutral backdrop to individual agency. Yet the acquisition of agency 
and wellbeing takes place not in a neutral context of broad social determinants, but in the context of specific socio-economic relations, which involve multidimensional power. Employing the notion of capabilities, whether taken directly from Sen or Nussbaum or more loosely in the general sense that wellbeing requires the capacity to act, there is a tendency to abstract those capabilities or capacities from their generative context. Hartley Dean has put this very simply in the following: 'in the space of capabilities the individual ... is objectively distanced from the relation of power within which her identity and her life chances must be constituted' (2009b: 267). Summing up a three-pronged critique of the capabilities approach, Dean (2009b: 267) argues: 'First, and in any event, human beings cannot be free from their dependency on other human beings. Second and third, under capitalist social relations of production, individuals can be free neither from hegemonic controls over their participation in the public realm, nor from the direct or indirect consequences of the exploitation of human labour.'

I think there is much of value in Dean's critical explication of the capabilities approach. He points out that it can 'emphasise the value of functionings that are not simply marketable. Nussbaum's list of central human functional capabilities includes, for example, "Being able to use the senses, to imagine, think and reason ... to laugh, to play, to enjoy recreational activities"' (2009b: 273). Dean's critique of capability is not simply 'that it is too easily inflected towards the imperative of the market economy, but that it is inherently liberal individualist' (2009b: 273). I would agree, but argue that, in addition, it places too much emphasis on rational cognitive action as a basis for agency and wellbeing and still neglects to consider both the relational and complex nature of emotionality and intersubjectivity exercised in the context of social movements and forces. As Mick Carpenter has noted, 'While (the capabilities approach) acknowledges group influences on individual capabilities, it does not explicitly sanction them at the collectivist level, e.g. the efforts of labour and other social movements, such as those of ethnic minorities, disabled people, or Lesbian and, Gay, Bisexual and Transgender (LBGT) to sustain a collective cultural integrity and resources in the context of a hostile society' (2009: 359).

Doyal and Gough, from their early work on human needs (1984, 1991), fully recognised that all needs are satisfied through relationships, and as noted by McGregor (2007: 322), 'whether these are satisfied through interactions with close relatives and friends, through personal or impersonal contacts with representatives of the state, or intermediaries in the market, or other relationship is then a matter for empirical verification in particular community and societal contexts'.

This question of which social relationships are constitutive of agency and of being well or just being well enough is an empirical one and a key question for research. There has been an explicit assumption in much wellbeing work taking 
a relational perspective that it is close personal relationships which are most important for wellbeing. It is often in the context of these 'close' relationships that individuals will express a deep sense of their personal wellbeing. Yet the resources and capabilities they mobilise in these relationships may be generated in the more 'distant' social relationships of social welfare provision and interactions with welfare professionals - that is, those relationships which may be productive of their welfare or their ability to 'do well'. These may be with strangers or more distant agents of the state in which interaction may be driven more by a social rights claim than the satisfaction of needs. However, whilst close relationships may be perceived as the natural home of thicker wellbeing, I think it is an open question as to which relationships are most productive of wellbeing. Just as the historical institutional contexts for wellbeing are varied, so is the salience of particular personal and social relationships. Opportunities for thick and thin wellbeing will have different resonances for different individuals in different contexts. The ability to be accepted in public by those more distant from us or to be able to feel the personal confidence simply to inhabit what can be experienced as challenging social spaces may be as central to being well and of having some form of agency as being locked into close but challenging dense personal relationships.

I think it may be helpful, then, to apply the notion of thick and thin needs to wellbeing and welfare, not as an a priori universal theory, but in the sense of a set of questions for empirical investigation about which relationships are constitutive of 'thick' and 'thin' wellbeing for particular individuals. A key issue would be how these relate to personal relationships, social groups or social movements. Dean (2009a: 316) notes, 'thicker kinds of wellbeing might be demanded from below', but there can equally be social demands for thinner rights-based social conditions constitutive of personal wellbeing, and this would mean we might need to attend to collective actions as well as individual agency in understanding wellbeing.

From this perspective, there is no necessary antinomy between wellbeing and welfare. Indeed, being well and doing well become different aspects of an integrated understanding of the relationship between the individual and the social. And beyond this, being well enough and doing well enough as understood by individuals themselves in specific contexts and social relationships can be a focus for understanding individual agency and for social policy. Such an approach would also need to be sensitive to forms of agency that are not directly actionoriented. Indeed, surrendering autonomy within supportive relationships can be a form of agency - 'you choose for me because you have a better knowledge than I do' or 'because I trust you' can be a form of agency directed at securing wellbeing. Equally, wellbeing experienced by individuals as a level of ability to operate autonomously does not necessarily equate to a desire simply for market participation or absence of supportive relations - indeed one of the interesting 
research questions around individual wellbeing is the level at which the experience of individual autonomy is dependent upon a backdrop of social conditions and relations which enable agency.

In terms of social and public policy, this might lead us to question the increasing reliance on approaches to wellbeing which place responsibility for being well with users of services seen as consumers and who, as such, are increasingly steered toward individualised and marketised solutions to problems of wellbeing. It suggests an understanding of wellbeing as a process which unfolds in a variety of contexts structured by close relations with significant others and distant relations with those who provide professional services and social goods and with the generalised strangers who we encounter as part of our social relationships.

\section{Conclusion}

Arguments that wellbeing should supplant welfare as a central aim of social and public policy are misconceived. Welfare is often relegated simply to economic utility and social protection in the form of state benefits. This is a limited account of the function of welfare in which use of welfare services is equated with dependency and lack of individual autonomy. Such arguments rely on highly normative constructions of the individual and the social and a view of agency as rational cognitive action oriented towards securing 'independence' and positive outcomes in the form of happiness. An alternative understanding of wellbeing influenced by psychosocial studies questions the separation of the individual and the social as distinct spheres and challenges assumptions that agency is only achieved through independent autonomous action. Instead a generative view of wellbeing and welfare points us to the importance of context and relations and the view that wellbeing is as much a process as an outcome. Both close and distant relations can be constitutive of ontological security. An over-reliance of rational action assumes the ability to abstract oneself from the immediacy of emotional and bodily specificity and a denial of the role of negative emotional and mutual dependencies. Wellbeing, however, draws as much on these experiences as on rational decision-making. A social and public policy which maintains social provisions for a range of personal circumstances beyond those of selfhelp and its assumed 'independence' are likely to be more supportive of genuine wellbeing.

\section{References}

Bauman, Z. (2003), Liquid Love: On the Frailty of Human Bonds, Cambridge: Polity Press.

Bevan, P. (2007), 'Researching wellbeing across disciplines: some key intellectual problems and ways forward', in I. Gough and A. McGregor (eds.), Wellbeing in Developing Countries: From Theory to Research, Cambridge: Cambridge University Press.

British Association for Counselling and Psychotherapy (BACP), see http://www.bacp.co.uk/ iapt/ (last accessed 16 June 2010). 
Cameron, D. (2010), Speech to the UK Treasury, see http://www.independent.co.uk/news/ uk/politics/cameron-defends-wellbeing-measure-2143595.html (last accessed 24 November, 2010).

Carpenter, M. (2009), 'The capabilities approach and critical social policy: lessons from the majority world?', Critical Social Policy 100, London: Sage, pp. 351-73.

Cooper, A. and Lousada, J. (2005), Borderline Welfare: Feeling and the Fear of Feeling in Modern Welfare, London: Karnac.

Dean, H. (2005), Social Policy, Oxford: Polity Press.

Dean, H. (2009a), 'Review of three books on wellbeing', Social Policy and Administration, 43: 3, $311-16$.

Dean, H. (2009b), 'Critiquing capabilities: the distractions of a beguiling concept', Critical Social Policy, 99: 261-78.

Dean, H. (2010), Understanding Human Need, Bristol: Policy Press.

Deci, E. and Ryan, M. (2006), 'Hedonia, eudaimonia, and well-being: an introduction', Journal of Happiness Studies, 9: 1, 1-11.

Doyal, L. and Gough, I. (1984), 'A theory of human needs', Critical Social Policy, 4: 6-38.

Doyal, L. and Gough, I. (1991), A Theory of Human Need, London: Macmillan.

Edwards, C. and Imrie, R. (2008), 'Disability and the implications of the wellbeing agenda: some reflections from the United Kingdom', Journal of Social Policy, 37: 3, 337-55.

Fromm, E. (2008), To Have or To Be?, London: Continuum Books.

Frosh, S. (2003), 'Psychosocial studies and psychology: is a critical approach emerging?', Human Relations, 56: 1547-67.

Furedi, F. (2003), Therapy Culture, London: Routledge.

Gough, I., McGregor, A. and Camfield, L. (2007), 'Theorising welfare in international development', in I. Gough and A. McGregor (eds.), Wellbeing in Developing Countries: From Theory to Research, Cambridge: Cambridge University Press.

HM Government (2000), Local Government Act 2000 c 22, London, HMSO.

HM Treasury (2008), Developments in the Economics of Well-Being, Treasury Economic Working Paper No. 4, November 2008, Surrey: Office of Public Sector Information.

Hoggett, P. (2001), 'Agency, rationality and social policy', Journal of Social Policy, 30: 1, 376.

Jordan, B. (2008), Welfare and Wellbeing: Social Value in Public Policy, Bristol: Policy Press.

McGregor, A. (2007), 'Researching wellbeing: from concepts to methodology', in I. Gough and A. McGregor (eds.), Wellbeing in Developing Countries: From Theory to Research, Cambridge: Cambridge University Press.

New Economics Foundation, see http://www.nationalaccountsofwellbeing.org, last accessed 10 November 2010.

Ryan, R. and Sapp, A. (2007), 'Basic psychological needs: a self-determination theory perspective on the promotion of wellness across development and cultures', in I. Gough and A. McGregor (eds.), Wellbeing in Developing Countries: From Theory to Research, Cambridge: Cambridge University Press.

Searle, B. (2008), Well-being: In Search of a Good Life? Bristol: Policy Press.

Siegrist, J. (2003), 'Subjective wellbeing: new conceptual and methodological developments in health-related social sciences', paper presented to ESF SCSS exploratory workshop, Income, Interactions and Subjective Wellbeing, Paris, 25-26 September 2003.

Sointu, E. (2005), 'The rise of an ideal: tracing changing discourses of wellbeing', The Sociological Review, 53: 2, 255-74.

Sointu, E. (2006), 'The search for wellbeing in alternative and complementary health practices', Sociology of Health and Illness, 2: 3, 330-49.

Stenner, P. (2010), 'Psychosocial studies without foundations: a transdisciplinary approach', keynote address, 3rd Psychosocial Network Conference, University of East London.

Stenner, P. and Taylor, D. (2008), 'Psychosocial welfare: reflections on an emerging field', Critical Social Policy, 28: 4, 415-37. 
Stiglitz, J., Sen, A. and Fitoussi, J. (2011), Commission on the Measurement of Economic Performance and Social Progress, www.stiglitz-sen-fitoussi.fr, last accessed 8 February 2011.

UNDP, see http://hdr.undp.org/en/humandev/, last accessed 8 February 2011.

Van Hoorn, A. (2007), 'A short introduction to subjective wellbeing', paper presented to the 'Is Happiness Measurable and What do those Measures Mean for Policy?', Conference, Rome, June 2007.

Williams, F. (1999), 'Good-enough principles for welfare', Journal of Social Policy, 28: 66787.

Wood, G. and Newton, J. (2005), 'From welfare to wellbeing regimes: engaging new agendas', paper presented to the 'New Frontiers of Social Policy' Conference, Arusha, 12-15 December 2005. 
Reproduced with permission of the copyright owner. Further reproduction prohibited without permission. 